\title{
Changes in Temperature Profile, Texture and Color of Pork Loin Chop during Pan-frying
}

\author{
Chunbao $\mathrm{Li}^{1}$, Yuxiang $\mathrm{Hu}^{1}$, Lin Tang ${ }^{1}$, Yuyu Dong ${ }^{1}$, Anguo Teng ${ }^{1,2}$, Xinglian $\mathrm{Xu}^{1}$, Baocai $\mathrm{Xu}^{3}$, \\ \& Guanghong Zhou ${ }^{1}$ \\ ${ }^{1}$ National Center of Meat Quality and Safety Control, MOST, Key Laboratory of Animal Products Processing, \\ MOA, College of Food Science and Technology, Nanjing Agricultural University, Nanjing, China \\ ${ }^{2}$ College of Food Engineering and Biotechnology, Tianjing University of Science and Technology, Tianjin, \\ China \\ ${ }^{3}$ State Key Laboratory of Meat Processing and Quality Control, Nanjing, China \\ Corresponding author: Guanghong Zhou, Key Laboratory of Meat Processing and Quality Control, Ministry of \\ Education, College of Food Science and Technology, Nanjing Agricultural University, Nanjing 210095, China. \\ Tel: 86-258-439-5376. E-mail: ghzhou@njau.edu.cn
}

Received: December 1, $2011 \quad$ Accepted: December 16, $2011 \quad$ Online Published: July 17, 2012
$\begin{aligned} & \text { doi:10.5539/jfr.v1n3p184 } \\ & \text { URL: http://dx.doi.org/10.5539/jfr.v1n3p184 }\end{aligned}$

This work was supported by 30901126, CARS-36-11B and the Priority Academic Program Development of Jiangsu Higher Education Institutions

\begin{abstract}
The aim of this work was to investigate changes in thermal profile, meat texture and color of pork chop during pan-frying with or without one turnover. Pork chops $\left(1.2 \mathrm{~cm}\right.$ thick) were individually pan-fried at $175^{\circ} \mathrm{C}$ for $75 \mathrm{~s}$ without turnover or $150 \mathrm{~s}$ with one turnover. Internal temperature, meat color and texture at 11 designated positions were tracked. During frying, temperature and cooking loss significantly increased $(\mathrm{P}<0.001)$, accompanied by a significant increase $(\mathrm{P}<0.001)$ in hardness, gumminess, chewiness and $\mathrm{L}^{*}$ value, together with a significant decrease $(\mathrm{P}<0.05)$ in springiness, cohesiveness, resilience and $\mathrm{a}^{*}$ value. Positions close to the periphery generally showed significantly higher $(\mathrm{P}<0.05)$ final temperatures, and significantly lower $(\mathrm{P}<0.05)$ hardness, gumminess, chewiness, $\mathrm{L}^{*}$ and $\mathrm{a}^{*}$ values than those close to the center. These results could explain variation in tenderness within the same sample when evaluating eating quality of cooked meat.
\end{abstract}

Keywords: color, thermal profile, pan frying, pork

\section{Practical Applications}

The paper showed significant differences in texture and color with different thermal transfer on different positions of the same pork steak. Color attributes show a certain relationship to texture and thermal transfer. It is possible to evaluate meat texture on the basis of color of cooked meat.

\section{Introduction}

Pan-frying is a very common cooking method for preparation of meat dishes and has an advantage of producing lower off-flavor without significant influence on other sensory attributes (pork flavor, tenderness, juiciness), compared to other high-temperature cooking method, e.g. grilling (Prestat, Jensen, McKeith, \& Brewer, 2002). Frying temperature is a very important factor in terms of meat flavor, cooking time and weight loss of products. Meinert, Andersen, Bredie, Bjergegaard and Aaslyng (2007) showed that lipid-derived volatiles dominated when samples were fried at $150{ }^{\circ} \mathrm{C}$ but Maillard-reaction derivatives prevailed when samples were fried at $250{ }^{\circ} \mathrm{C}$. However, too high frying temperature could induce the formation of heterocyclic amines in meat products and $175{ }^{\circ} \mathrm{C}$ could be the upper limit when the safety of meat products is taken as granted (Skog, Steineck, Augustsson, \& Jagerstad, 1995).

Thermal profile and weight loss of meat products during cooking has been extensively studied (Ikediala, Correia, Fenton, \& Ben-Abdallah, 1996; Zorrilla \& Singh, 2003; Goni \& Salvadori, 2010). Ikediala et al. (1996) mathematically modeled heat transfer in meat patties during single-sided pan-frying with or without turnover and 
showed a difference in temperature change on bottom side, midpoint and top side. Zorrilla and Singh (2003) modeled a two-dimension thermal transfer profile during double-side cooking of meat patties, i.e., heat transfer occurred radially from the periphery to the midpoint and axially from the bottom and top sides to the middle. Goni and Salvadori (2010) also modeled temperature profile and weight losses during meat roasting. These studies gave us a good knowledge of heat and mass transfer during meat cooking. However, less has been known about changes in meat texture and color with heat and mass transfer during frying of pork chops.

Therefore, the objective of the present study was to investigate changes in thermal profile, meat texture and color during pan-frying of pork at $175^{\circ} \mathrm{C}$ for $150 \mathrm{~s}$ with one turnover at $75 \mathrm{~s}$.

\section{Materials and Methods}

\subsection{Sampling}

Five longissimus muscles between the first thoracic and the last lumbar vertebrae were removed from pig carcasses at approximately $8 \mathrm{~h}$ postmortem from a local market. Before sampling, hot carcasses were placed at $15^{\circ} \mathrm{C}$ in which the onset of rigor mortis of muscle may be completed because $\mathrm{pH}$ values of muscle were around 5.6. Under this condition, cold shortening could be avoided (Savell, Mueller, \& Baird, 2005). Each longissimus muscle was divided into 12 pieces of $1.2 \mathrm{~cm}$-thick chops perpendicular to muscle direction.

\subsection{Pan-frying}

To investigate changes in temperature profile, meat texture and color inside pork chop before and after turnover, two trials were included.

In Trial 1 (frying for $75 \mathrm{~s}$, without turnover), 6 chops from the same animal were individually fried in $175{ }^{\circ} \mathrm{C}$ rapeseed oil (oil layer was approximately $1 \mathrm{~mm}$ thick) in a flat-bottomed frying pan for $75 \mathrm{~s}$. During frying, muscle temperatures were tracked at $1 \mathrm{~s}$ interval with two temperature probes (Pt 100, Testo AG, Germany) connected with a Testo thermometer (Testo 735-2, Testo AG, Germany) at 11 different positions on the 6 $\mathrm{mm}$-thick plane (Figure 1). The temperatures of 11 designated positions were tracked on 6 different chops with 1 or 2 positions each time (Table 1). After frying, chops were chilled to room temperature $\left(15^{\circ} \mathrm{C}\right)$ and cooking loss was calculated as the percentage of chop weight loss before and after frying. Then cooked chops were cut into two pieces at $6 \mathrm{~mm}$ thickness for further meat color and texture measurements.

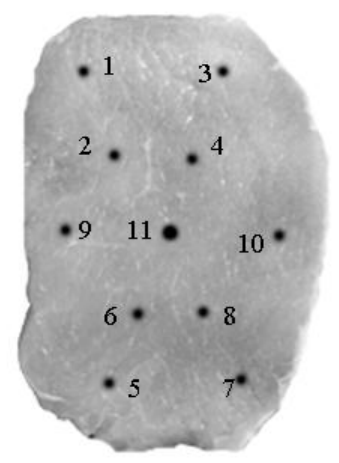

Figure 1. Positions selected for temperature, texture and color measurements

Table 1. Experimental design $(\mathrm{N}=5)$

\begin{tabular}{ccccc}
\hline Trial 1 & Trial 2 & Temperature & Color & Texture \\
\hline Chop 1 & Chop 7 & 1,2 & 1 to 11 & 1 to 11 \\
Chop 2 & Chop 8 & 3,4 & 1 to 11 & 1 to 11 \\
Chop 3 & Chop 9 & 5,6 & 1 to 11 & 1 to 11 \\
Chop 4 & Chop 10 & 7,8 & 1 to 11 & 1 to 11 \\
Chop 5 & Chop 11 & 9,10 & 1 to 11 & 1 to 11 \\
Chop 6 & Chop 12 & 11 & 1 to 11 & 1 to 11 \\
\hline
\end{tabular}

In Trial 2 (frying for $150 \mathrm{~s}$, with one turnover at $75 \mathrm{~s}$ ), another 6 chops from the same animal were fried in the above medium on one side for $75 \mathrm{~s}$ and then on the other side for another $75 \mathrm{~s}$. Temperature at the same positions 
were tracked as described in Trial 1 before and after the turnover. Weighing and cutting were also done as above described.

\subsection{Color Measurement}

After cutting, newly cutting surface of cooked samples was bloomed in the air for approximately 20 min. Meat color at 11 designated positions was measured with a Minolta colorimeter (CR-300; Minolta Camera Co., Osaka, Japan) with illuminant D65, a $0^{\circ}$ viewing angle and an $8 \mathrm{~mm}$ port/viewing area. Before measurement, the colorimeter was calibrated with a white tile ( $\bmod \mathrm{CR}-\mathrm{A} 43)$. Color coordinates (CIE L*, $\left.\mathrm{a}^{*}, \mathrm{~b}^{*}\right)$ were recorded.

\subsection{Texture Analysis}

Texture of cooked samples was analyzed with a TA. XT plus texture analyzer (Stable Micro Systems Ltd., Godalming, UK) on the cutting surface of the fried half part in Trial 1 and of the first fried half part in Trial 2. Meat samples were penetrated with a $5.0 \mathrm{~mm}$-diameter cylinder stainless probe (P5) by a trigger force of $0.02 \mathrm{~N}$ at an acquisition rate of $200 \mathrm{pps}$ (point per second). The test parameters were set as follows: pre test speed, 2.0 $\mathrm{mm} / \mathrm{s}$; test speed, $0.5 \mathrm{~mm} / \mathrm{s}$; post test speed, $5.0 \mathrm{~mm} / \mathrm{s}$. The penetration distance was $5.0 \mathrm{~mm}$. Texture profile (hardness, springiness, gumminess, chewiness and resilience) was analyzed with the software Texture Expert Exceed (Stable Micro Systems Ltd, Godalming, UK).

\subsection{Statistical Analyses}

Principle component analysis (PCA) was performed with the program Unscrambler X (version 10.1 CAMO software AS, Oslo, Norway, 2010) to investigate the differences in texture and color among designated positions in all samples. All the variables were standardized by multiplying by $1 / \mathrm{SD}$ and seven components were selected. On scores plot, samples were grouped by designated positions.

Effect of position on muscle temperature, texture and color attributes were evaluated by one-way analysis of variance. Least squares means of 11 positions were compared by Bonferroni's method at the significance level of 0.05 (Abdi, 2007) with the program SAS 8.12 (2003).

\section{Results}

\subsection{Thermal Change and Cooking Loss during Frying}

Changes in muscle temperature at 11 designated positions were shown in Figure 2. Thermal change in chops during the first frying stage (before turnover) in Trial 2 was similar to that in Trial 1, and thus only results in Trial 2 was shown here. Positions close to the periphery (positions $1,3,5,7$ and 10) showed higher $(P<0.05)$ temperature than those close to the center (positions 2, 4, 6, 8 and 11) at the first stage (before turnover). At the second stage (after turnover), the temperature differences between positions close to the periphery (positions 1, 3 , $5,7,9$ and 10) and those close to the center (positions 2, 4 and 11) increased $(P<0.05)$.

Cooking loss of pork chops increased with frying time. Cooking loss after $150 \mathrm{~s}$ frying was twice as high as that of 75 s frying $(24.75 \pm 3.00 \%$ vs. $11.26 \pm 2.19 \%$ for $150 \mathrm{~s}$ and $75 \mathrm{~s}$, respectively, $P<0.001)$.

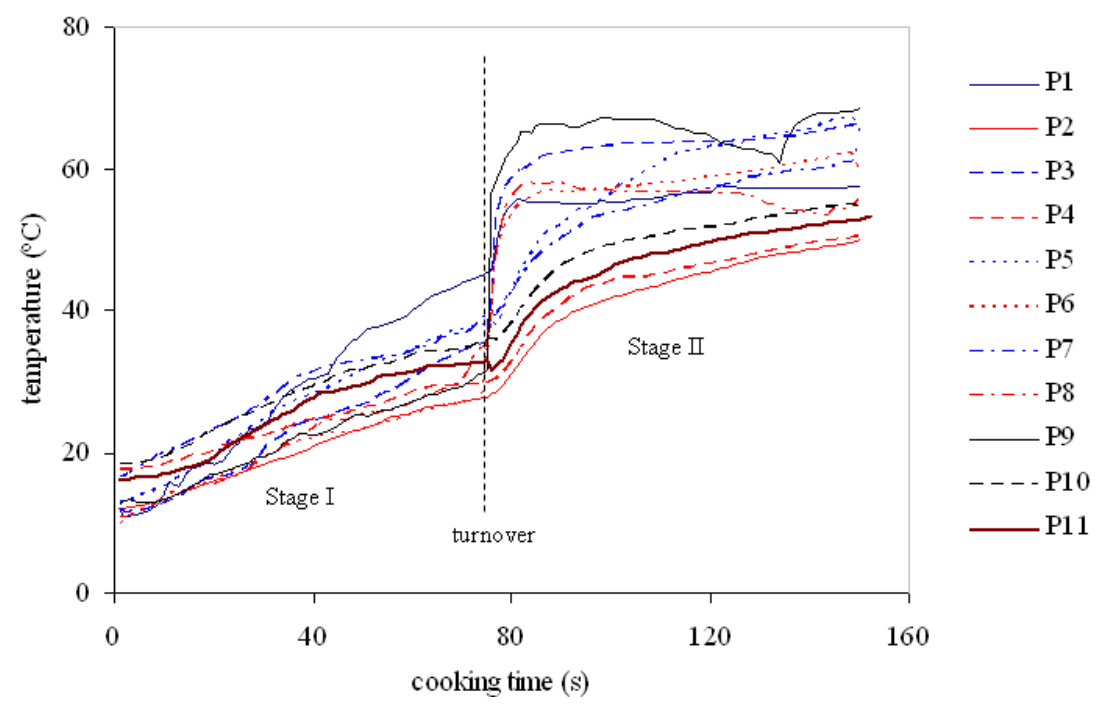

Figure 2. Thermal profile during frying with one turnover at $75 \mathrm{~s}$ 


\subsection{PCA Analysis}

Principle component analysis showed that the first three components accounted for $91.6 \%$ of variations in color and texture variables in Trial 1 and $71.3 \%$ in Trial 2 (Figure 3).
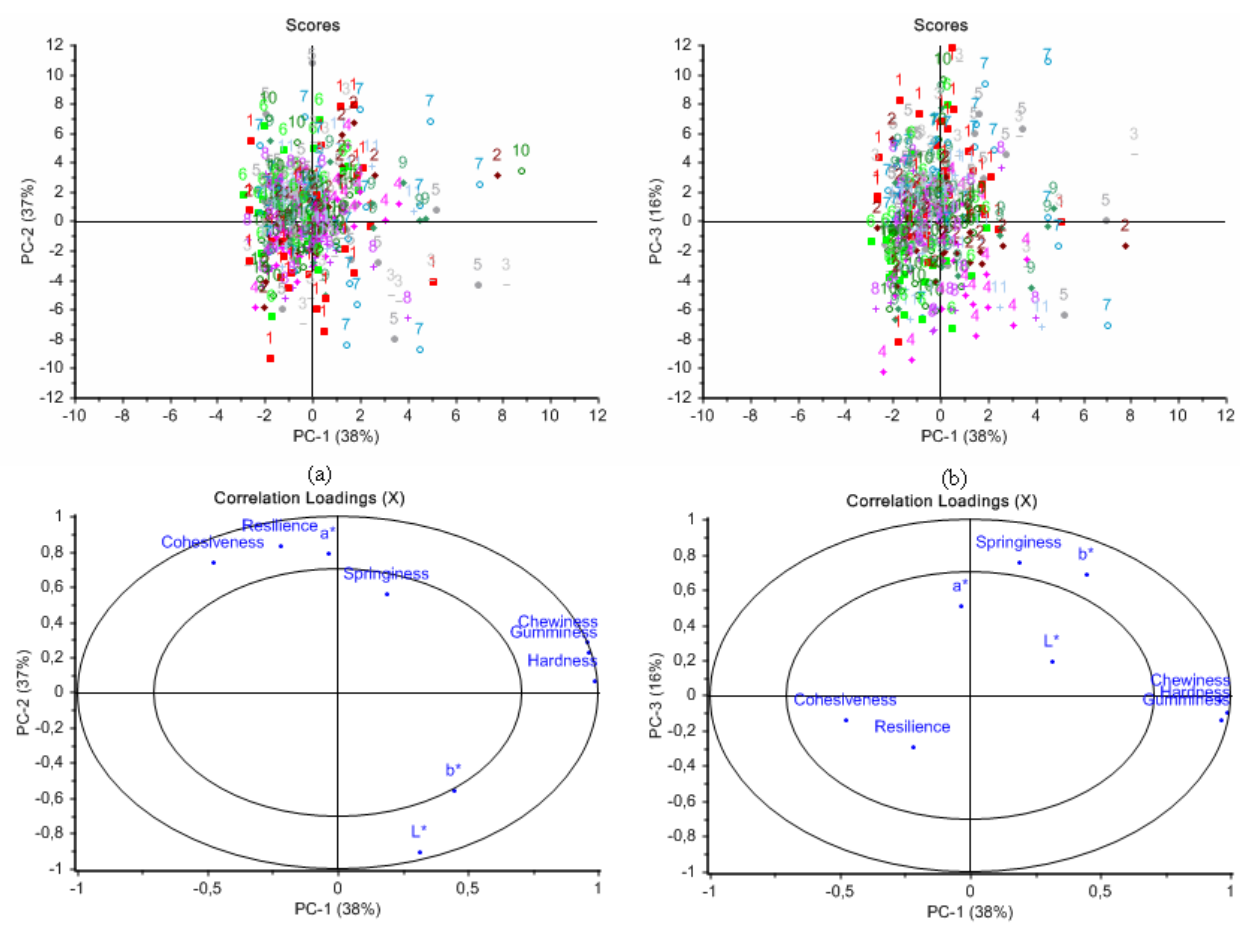

(c)

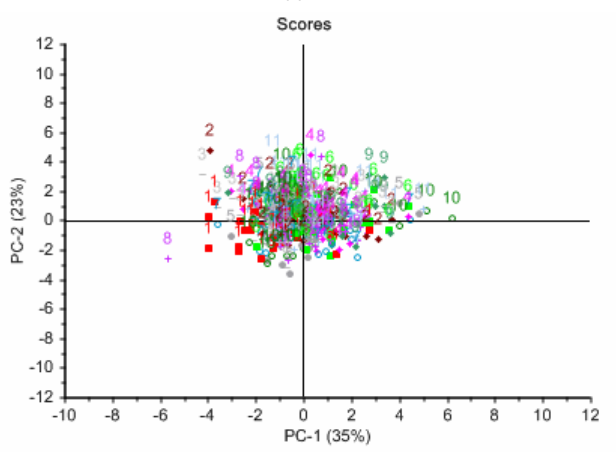

(d)

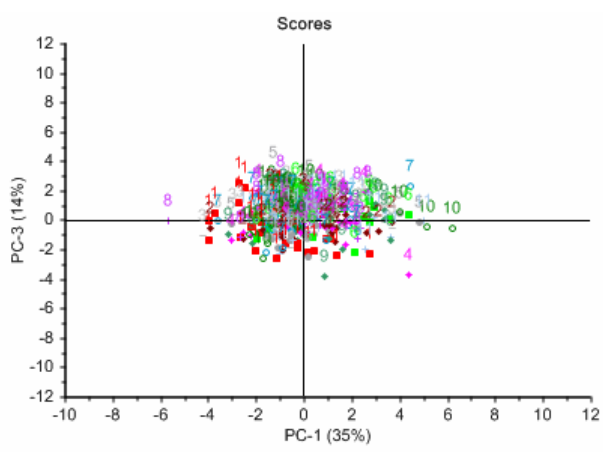

(e)
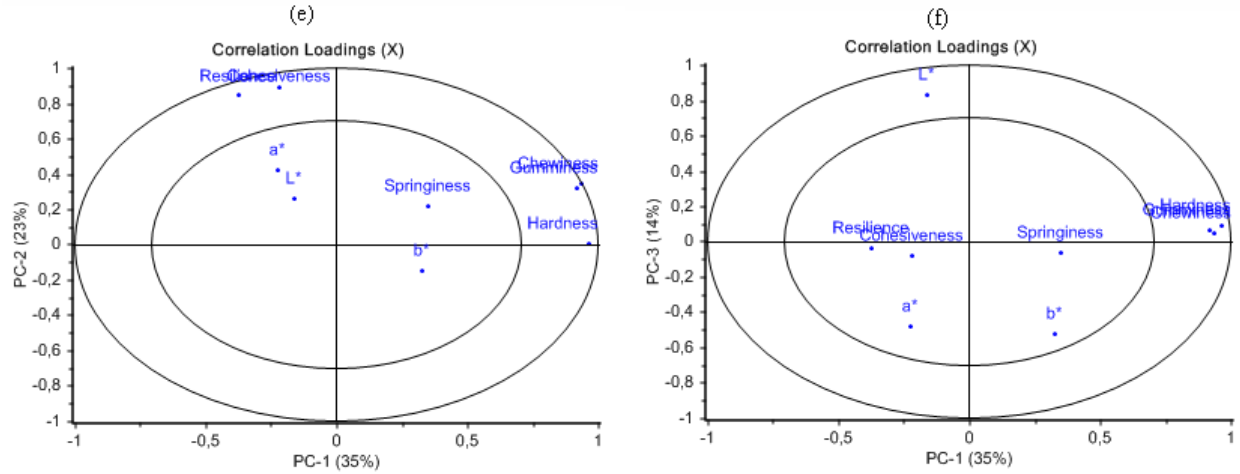

(g)

(h)

Figure 3. Principle component analysis of texture and color data

(a) to (d) for Trial 1: (a) scores plot (PC1 and PC2); (b) scores plot (PC1 and PC3); (c) correlation loadings plot (PC1 and PC2); (d) correlation loadings plot (PC1 and PC3)

(e) to (h) for Trial 2: (e) scores plot (PC1 and PC2); (f) scores plot (PC1 and PC3); (g) correlation loadings plot (PC1 and PC2); (h) correlation loadings plot (PC1 and PC3) 
In Trial 1, PC1 accounted mainly for variations in hardness, gumminess and chewiness (Figure $3 \mathrm{c}$ and d), PC2 for color attributes (CIE L*, $a^{*}, b^{*}$ ), resilience and cohesiveness (Figure $3 \mathrm{c}$ ), and PC 3 for springiness and $b^{*}$ (Figure 3d). Positions 2, 9, and 10 showed great variation in the first dimension (PC1, Figure $3 \mathrm{a}$ and b), but positions 1, 6 and 8 varied mainly along with the second dimension (PC2, Figure 3a) and positions 4 and 8 varied along with the third dimension (PC3, Figure 3b). Positions 3, 5 and 7 varied in both the second and third dimensions (PC2 and PC3, Figure 3a and b). Position 11 showed small variation among individual samples.

In Trial 2, PC1 also accounted mainly for the variations in hardness, gumminess and chewiness, $\mathrm{PC} 2$ for resilience and cohesiveness, and $\mathrm{PC} 3$ for $\mathrm{L}^{*}$. In the selected three dimensions, all positions seemed to vary less, compared to those in Trial 1.

\subsection{Meat Texture}

At the first stage (Trial 1), several positions showed significant differences in springiness $(P<0.001)$, cohesiveness $(P<0.001)$ and resilience $(P=0.016)$. Springiness seemed slightly higher at the positions close to the periphery (positions 1, 3, 5, 7 and 9) than those close to the center (positions 2, 4, 6 and 8), with the lowest value at position 8 and the highest at position $7(P<0.05$, Table 2). However, cohesiveness and resilience at positions 1 , $3,5,7$ and 9 were slightly lower than those at positions $2,4,6,8,10$ and 11 . Cohesiveness was the lowest at position 3 and the highest at positions 6 and $11(P<0.05$, Table 2). Resilience was the lowest at positions 3 and 7 and the highest at positions 2, 6, 10 and $11(P<0.05$, Table 2). Hardness, gumminess and chewiness did not show significant difference among the 11 designated positions $(P>0.05)$.

At the second stage (Trial 2), hardness, gumminess and chewiness increased greatly $(P<0.001)$, but springiness, cohesiveness and resilience declined $(P<0.05)$. There were significant differences in hardness $(P<0.001)$, springiness $(P=0.006)$, gumminess $(P<0.001)$ and resilience $(P=0.005)$ among different positions. Hardness, gumminess and chewiness at positions $1,3,5$ and 7 were numerically lower than those at positions 2, 4, 6, 8, 9, 10 and 11, with the lowest value at position 1 and the highest value at position $6(P<0.001$, Table 2$)$. Springiness at positions 1,5 and 10 was lower $(P<0.05)$ than that at positions 3,6 and 8 . Resilience was the highest at position 11 and the lowest at position $7(P<0.05)$. Cohesiveness was not significantly different $(P>0.05)$ among all the designated positions.

Table 2. Changes in meat texture and color attributes of pork chop during pan-frying (Means \pm standard errors, $\mathrm{N}=5)$

\begin{tabular}{|c|c|c|c|c|c|c|c|c|c|c|c|c|c|}
\hline \multirow[t]{2}{*}{ Items } & \multicolumn{11}{|c|}{ Positions } & \multirow[t]{2}{*}{ SE } & \multirow{2}{*}{$\begin{array}{l}P \\
\text { value }\end{array}$} \\
\hline & 1 & 2 & 3 & 4 & 5 & 6 & 7 & 8 & 9 & 10 & 11 & & \\
\hline \multicolumn{14}{|c|}{ Frying for $75 \mathrm{~s}$ without turn-over } \\
\hline Hardness (N) & 2.72 & 2.84 & 2.99 & 2.81 & 2.85 & 2.61 & 3.05 & 2.57 & 2.74 & 2.69 & 2.64 & 0.23 & 0.442 \\
\hline Springiness & $0.85^{a b}$ & $0.83^{a b}$ & $0.85^{a b}$ & $0.82^{a b}$ & $0.86^{a b}$ & $0.83^{a b}$ & $0.87^{a}$ & $0.81^{b}$ & $0.84^{a b}$ & $0.82^{a b}$ & $0.86^{a b}$ & 0.01 & $<0.001$ \\
\hline Cohesiveness & $0.68^{a}$ & $0.70^{a b}$ & $0.67^{a}$ & $0.69^{a b}$ & $0.70^{a b}$ & $0.72^{b}$ & $0.70^{a b}$ & $0.69^{a b}$ & $0.69^{a b}$ & $0.70^{a b}$ & $0.72^{b}$ & 0.01 & $<0.001$ \\
\hline Gumminess & 187.12 & 200.49 & 200.52 & 197.01 & 197.65 & 189.95 & 211.64 & 178.08 & 191.27 & 191.72 & 192.94 & 14.87 & 0.658 \\
\hline Chewiness & 160.82 & 166.92 & 171.44 & 161.27 & 170.67 & 157.94 & 185.56 & 144.62 & 161.21 & 157.84 & 166.89 & 12.68 & 0.204 \\
\hline Resilience & $0.28^{a}$ & $0.30^{b}$ & $0.28^{a}$ & $0.29^{a b}$ & $0.29^{a b}$ & $0.30^{b}$ & $0.28^{a}$ & $0.29^{a b}$ & $0.29^{a b}$ & $0.30^{b}$ & $0.30^{b}$ & 0.005 & 0.016 \\
\hline $\mathrm{L}^{*}$ & 60.77 & 57.65 & 63.05 & 65.11 & 60.92 & 63.3 & 62.93 & 66.16 & 67.19 & 70.17 & 66.64 & 2.79 & 0.079 \\
\hline$a^{*}$ & 13.08 & 13.04 & 12.72 & 11.34 & 11.18 & 11.67 & 13.31 & 10.1 & 11.61 & 9.49 & 11.50 & 1.20 & 0.141 \\
\hline$b^{*}$ & 10.64 & 8.95 & 11.56 & 11.64 & 8.59 & 9.80 & 10.46 & 10.54 & 12.73 & 11.81 & 11.51 & 0.90 & 0.084 \\
\hline \multicolumn{14}{|c|}{ Frying for $150 \mathrm{~s}$ with one turn-over } \\
\hline Hardness (N) & $10.33^{a}$ & $12.56^{b c}$ & $11.46^{a b}$ & $13.12^{b c}$ & $12.01^{a b c}$ & $13.45^{c}$ & $11.65^{a b c}$ & $12.33^{b c}$ & $12.89^{b c}$ & $12.76^{b c}$ & $13.02^{b c}$ & 0.51 & $<0.001$ \\
\hline Springiness & $0.77^{a}$ & $0.81^{a b}$ & $0.82^{b}$ & $0.81^{a b}$ & $0.79^{a}$ & $0.82^{b}$ & $0.80^{a b}$ & $0.82^{b}$ & $0.81^{a b}$ & $0.79^{a}$ & $0.81^{a b}$ & 0.01 & 0.006 \\
\hline Cohesiveness & 0.55 & 0.56 & 0.57 & 0.55 & 0.55 & 0.56 & 0.54 & 0.55 & 0.56 & 0.54 & 0.56 & 0.01 & 0.068 \\
\hline Gumminess & $581.19^{a}$ & $701.49^{b c}$ & $656.96^{a b c}$ & $735.14^{b c}$ & $668.06^{a b c}$ & $766.95^{c}$ & $641.69^{a b}$ & $690.09^{a b c}$ & $734.97^{b c}$ & $701.52^{b c}$ & $740.65^{b c}$ & 28.04 & $<0.001$ \\
\hline Chewiness & $449.74^{a}$ & $564.67^{b c}$ & $541.43^{a b c}$ & $595.49^{b c}$ & $530.13^{a b c}$ & $623.07^{c}$ & $515.92^{a b c}$ & $559.46^{b c}$ & $596.73^{b c}$ & $554.04^{b c}$ & $602.58^{b c}$ & 24.67 & $<0.001$ \\
\hline Resilience & $0.22^{a b}$ & $0.22^{a b}$ & $0.22^{a b}$ & $0.22^{a b}$ & $0.21^{a b}$ & $0.22^{a b}$ & $0.19^{a}$ & $0.21^{a b}$ & $0.22^{a b}$ & $0.21^{a b}$ & $0.23^{b}$ & 0.01 & 0.005 \\
\hline $\mathrm{L}^{*}$ & $72.23^{a}$ & $73.52^{a b}$ & $73.98^{b}$ & $74.04^{b}$ & $73.83^{a b}$ & $74.59^{b}$ & $73.97^{b}$ & $74.90^{b}$ & $73.58^{a b}$ & $74.32^{b}$ & $74.06^{b}$ & 0.42 & $<0.001$ \\
\hline$a^{*}$ & $6.09^{a}$ & $6.81^{a b}$ & $6.50^{a b}$ & $7.18^{b}$ & $6.00^{a}$ & $6.53^{a b}$ & $6.13^{a}$ & $6.68^{a b}$ & $6.11^{a}$ & $6.87^{a b}$ & $7.08^{a b}$ & 0.27 & $<0.001$ \\
\hline$b^{*}$ & 12.19 & 11.88 & 12.12 & 11.81 & 12.49 & 11.92 & 12.00 & 11.78 & 12.25 & 11.49 & 11.75 & 0.23 & 0.446 \\
\hline
\end{tabular}




\subsection{Meat Color and Crust Formation}

At the first stage (Trial 1), meat color $\left(\mathrm{L}^{*}, \mathrm{a}^{*}, \mathrm{~b}^{*}\right)$ did not show significant differences among all the positions $(P>0.05$, Table 2). However, there was a thin brown layer along with the periphery (Figure $4 \mathrm{c}$ ). Meanwhile, a layer of crust was formed on the surface that had a direct contact with oil and pan (Figure $4 \mathrm{~b}$ ).

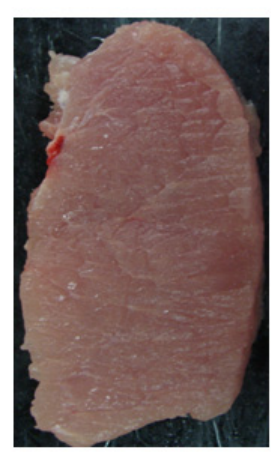

(a)

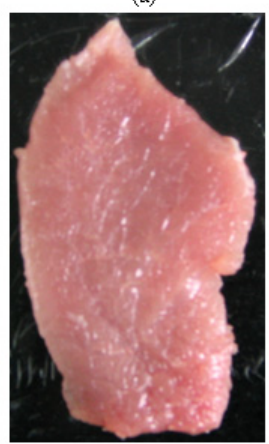

(d)

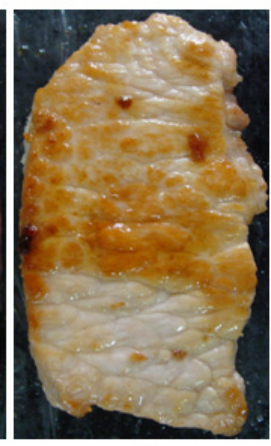

(b)

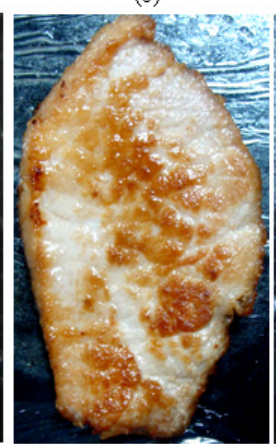

(e)

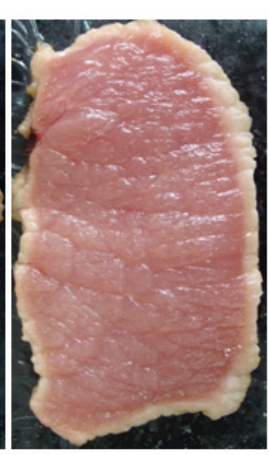

(c)

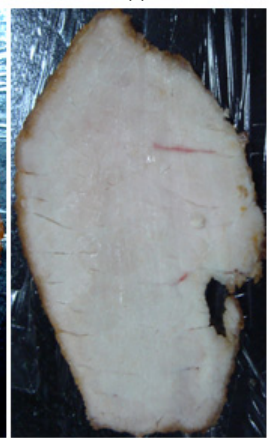

(f)

Figure 4. Meat color change and crust formation during frying

(a) and (d) raw meat; (b) and (e) crust formation; (c) and (f) cutting surface after $75 \mathrm{~s}$ and $150 \mathrm{~s}$ frying, respectively

At the second stage (Trail 2), the whole cutting surface became brown (Figure 4f) with much higher $\mathrm{L}^{*}$ value but lower a* value $(P<0.001$, Table 2$)$. Position showed a significant effect on $\mathrm{L}^{*}$ value $(P<0.001)$ and a* value $(P<0.001)$. Lightness $\left(\mathrm{L}^{*}\right.$ value) at position 1 was the lowest $(P<0.05)$ but there was no significant difference $(P>0.05)$ in $\mathrm{L}^{*}$ value among the other 10 positions. Redness (a* value) at positions $1,3,5,7$ and 9 was numerically higher than that at other positions, with the highest value at position $4(P<0.05$, Table 2$)$. There was no significant difference $(P>0.05$, Table 2$)$ in $\mathrm{b}^{*}$ value among all the designated positions. In addition, crust was formed on both sides (Figure 4e).

\section{Discussion}

The main purpose of the present study was to investigate the variations in thermal transfer, texture and color at different positions of pork chop during pan-frying. To avoid the formation of heterocyclic amines that had been reported (Skog et al., 1995), we selected a moderate frying temperature $\left(175^{\circ} \mathrm{C}\right)$ and much shorter time $(150 \mathrm{~s})$.

On the basis of the final temperature, the doneness of 11 designated positions of the fried samples varied from medium (positions close to the periphery) to rare (positions close to the center), but the outermost layer could be very well done (AMSA, 1995). This could explain variation in texture and color as discussed below, and even shear force value or sensory tenderness score within the same sample when we evaluate eating quality of cooked meat. The temperature difference among positions in the present study was similar to Zorrilla and Singh (2003). During frying, thermal transfer took place from the cooking medium (oil) to the bottom side of meat sample (Zorrilla \& Singh, 2003). At the same time, thermal transfer also happened from the hot air above the cooking medium to the periphery of pork chops (Zorrilla \& Singh, 2003). Inside pork chops, thermal transfer continued mainly by water, as well as fat and proteins (Baghe-Khandan \& Okos, 1981). However, water, fat and protein in muscle showed different thermal conductivity, with the highest for water $(\sim 0.65$, conductivity increases with temperature below $\left.70{ }^{\circ} \mathrm{C}\right)$, the lowest for fat $(\sim 0.16$, conductivity decreases with temperature) and the 
intermediate for protein $(\sim 0.19$, conductivity increases with temperature) (Baghe-Khandan \& Okos, 1981). The positions close to the periphery received more heat than those close to the center and thus showed higher temperature.

During frying, hardness, gumminess and chewiness increased but cohesiveness decreased. This may be ascribed to moisture loss, denaturation of myofibrillar proteins and collagen shrinkage when meat temperature increased (Martens, Stabursvik, \& Martens, 1982; Palka \& Daun, 1999). In addition, the positions close to the periphery received more heat and had higher temperature than those close to the center. This would be expected to cause more myosin, actin and collagen susceptible to denaturation and shrinkage (Martens et al., 1982; Palka \& Daun, 1999) and result in relatively high hardness, gumminess and chewiness at positions close to the periphery. Crust formation, which is typically characteristic of fried food (Sosa-Morales, Orzuna-Espiritu, \& Velez-Ruiz, 2006), could also affect meat texture. However, the fact was opposite, which may be attributed to the absorption of more oil at those positions because a certain amount of oil would be absorbed in meat samples during pan-frying (Clausen \& Ovesen, 2005).

During frying, $\mathrm{L}^{*}$ value increased but $\mathrm{a}^{*}$ decreased. This could be explained by heat-induced myoglobin degradation (a reduction in deoxyMb and oxyMb and an increase in globin haemochromogen, metMb and sulfMb) and the increase in the capacity to reflect the light (Fox, 1966; Garcia-Segovia, Andres-Bello, \& Martinez-Monzo, 2007; Sosa-Morales et al., 2006). The differences in a* values among 11 designated positions could be also explained by heat induced myoglobin degradation. Positions close to the periphery showed relatively low a* value, which may be attributed to the formation of more globin haemochromogen and metMb (Sosa-Morales et al., 2006).

\section{References}

Abdi, H. (2007). Bonferroni and sidok correlations for multiple comparisons. In, M. J. Salkind (ed.). Encyclopedia of Measurement and Statistics. Thousand Oaks, CA, Sage.

American Meat Science Association (AMSA). (1995). Research guidelines for cookery, sensory evaluation and instrumental tenderness measurements of fresh meat. Chicago, IL: American Meat Science Association and National Live Stock and Meat Board.

Baghe-Khandan, M., \& Okos, M. R. (1981). Effect of cooking on the thermal conductivity of whole and ground lean beef. Journal of Food Science, 46, 1302-1305. http://dx.doi.org/10.1111/j.1365-2621.1981.tb04159.x

Clausen, I., \& Ovesen, L. (2005). Changes in fat content of pork and beef after pan-frying under different conditions. Journal of Food Composition and Analysis, 18, 201-211. http://dx.doi.org/10.1016/j.jfca.2004.03.024

Fox, J. B. (1966). Chemistry of meat pigments. Journal of Agricultural and Food Chemistry, 14, 207-210. http://dx.doi.org/10.1021/jf60145a003

Garcia-Segovia, P., Andres-Bello, A., \& Martinez-Monzo, J. (2007). Effect of cooking method on mechanical properties, color and structure of beef muscle (M. pectoralis). Journal of Food Engineering, 80, 813-821. http://dx.doi.org/10.1016/j.jfoodeng.2006.07.010

Goni, S. M., \& Salvadori, V. (2010). Prediction of cooking times and weight losses during meat roasting. Journal of Food Engineering, 100, 1-11. http://dx.doi.org/10.1016/j.jfoodeng.2010.03.016

Ikediala, J. N., Correia, L. R., Fenton, G. A., \& Ben-Abdallah, N. (1996). Finite element modeling of heat transfer in meat patties during single-sided pan-frying. Journal of Food Science, 61, 796-802. http://dx.doi.org/10.1111/j.1365-2621.1996.tb12205.x

Martens, H., Stabursvik, E., \& Martens, M. (1982). Texture and color changes in meat during cooking related to thermal denaturation of muscle proteins. Journal of Texture Studies, 13, 291-309. http://dx.doi.org/10.1111/j.1745-4603.1982.tb00885.x

Meinert, L., Andersen, L. T., Bredie, W. L. P., Bjergegaard, C., \& Aaslyng, M. D. (2007). Chemical and sensory characterization of pan-fried pork flavor: interactions between raw meat quality, aging and frying temperature. Meat Science, 75, 229-242. http://dx.doi.org/10.1016/j.meatsci.2006.07.004

Palka, K., \& Daun, H. (1999). Changes in texture, cooking losses, and myofibrillar structure of bovine M. $\begin{array}{lllll}\text { semitendinosus during } & \text { 237-243. }\end{array}$ http://dx.doi.org/10.1016/S0309-1740(98)00119-3

Prestat, C., Jensen, J., McKeith, F. K., \& Brewer, M. S. (2002). Cooking method and endpoint temperature 
effects on sensory and color characteristics of pumped pork loin chops. Meat Science, 60, 395-400. http://dx.doi.org/10.1016/S0309-1740(01)00150-4

SAS. (2003). Statistical Analysis Software for Windows (Version 8.12). SAS Institute Inc., Cary, NC, USA.

Savell, J. W., Mueller, S. L., \& Baird, B. E. (2005). The chilling of carcasses. Meat Science, 70, 449-459. http://dx.doi.org/10.1016/j.meatsci.2004.06.027

Skog, K., Steineck, G., Augustsson, K., \& Jagerstad, M. (1995). Effect of cooking temperature on the formation of heterocyclic amines in fried meat products and pan residues. Carcinogenesis, 16, 861-867. http://dx.doi.org/10.1093/carcin/16.4.861

Sosa-Morales, M. E., Orzuna-Espiritu, R., \& Velez-Ruiz, J. F. (2006). Mass, thermal and quality aspects of deep-fat frying of pork meat. Journal of Food Engineering, 77, 731-738. http://dx.doi.org/10.1016/j.jfoodeng.2005.07.033

Zorrilla, S. E., \& Singh, R. P. (2003). Heat transfer in double-sided cooking of meat patties considering two-dimensional geometry and radial shrinkage. Journal of Food Engineering, 57, 57-65. http://dx.doi.org/10.1016/S0260-8774(02)00273-X 